\title{
EL EXPRESIONISMO ALEMÁN: UNA APROXIMACIÓN HISTÓRICA
}

\section{GERMAN EXPRESSIONISM: A HISTORICAL APPROACH}

\author{
María Magdalena Ziegler Delgado. Universidad Metropolitana. Caracas, \\ Venezuela. \\ buzonziegler@gmail.com
}

\section{RESUMEN}

Este artículo resume una exhaustiva revisión bibliográfica de las referencias teóricas e históricas usadas para la definición del expresionismo alemán. En él están las compiladas las principales contribuciones de los más reconocidos historiadores en el área de la Historia del arte.

Palabras Clave: Expresionismo alemán, Historia del arte, teoría.

\section{ABSTRACT}

This article summaries an exhaustive bibliographical review of the main theoretical and historical references through which German expressionism is defined. In it are the main contributions of the most respected historians in the area of Art History are compiled.

Keywords: German Expressionism, History of Art, theory.

Cómo citar el artículo:

Ziegler Delgado, M. M. (2014). El Expresionismo alemán: una aproximación histórica. Revista de Ciencias de la Comunicación e Información, 19, 1-12. http://doi.org/10.35742/revistacccomunicacioneinformacion.2014.19.1-12

\section{INTRODUCCIÓN}

Es una tarea bastante ardua hablar del Expresionismo, sobre todo, porque es imprescindible explicar el porqué de este nombre tan singular para un movimiento artístico. Decimos que es singular, porque normalmente todos creemos estar absolutamente seguros de que toda obra de arte implica expresión y, si esto es así, toda obra de arte, a lo largo de la historia, es sin dudas expresionista.

Aquí comienzan las implicaciones singulares de este movimiento que ni siquiera fue tal en el sentido en el que lo fue el Futurismo o el Surrealismo, por ejemplo. Nunca hubo un único grupo exclusivamente expresionista. De hecho, podríamos afirmar

\footnotetext{
${ }^{1}$ María Magdalena Ziegler Delgado: Consultora en Experiencia eLearning. Académica en el área de Historia del Arte y la Cultura. Asesora SeHablaArte.com.
} 
que los artistas que hoy consideramos parte de este movimiento trabajaron de una manera más libre y menos normada de lo que previeron el resto de las llamadas Vanguardias Heroicas.

Pero volvamos al asunto del nombre, de ese epíteto ya secular que se le otorgó a un grupo de individuos en las primeras décadas del siglo XX y que normalmente se endilga también a toda manifestación artística. Regresemos en el tiempo al ímpetu de las propuestas de finales del siglo XVIII en lo que es hoy Alemania, conocidas como Sturm \& Drang o Tormenta y Pasión. Sin duda, éste había sido "un intento pionero de romper con el dominio que la cultura mediterránea ejercía sobre un pueblo del norte, y los expresionistas alemanes de principios del siglo XX estaban embebidos de su literatura e ideas". ${ }^{2}$ A finales del siglo XVIII y comienzos del XIX nos hallamos ante un grupo de hombres que claman por la liberación del espíritu con el objeto de que éste pueda trascender. En cierto sentido esta búsqueda debe remitirnos al milenario propósito de todo cristiano: salvar las barreras de la muerte y alcanzar la vida eterna. En el Romanticismo, la vida eterna se entendió en términos de trascendencia terrenal a través de las acciones del espíritu ${ }^{3}$. Más tarde, el Expresionismo, digno heredero de sus abuelos alemanes de siglos anteriores, escoge esta misma senda, pues en ella reside el convulso camino al interior humano. Claro que, esto no resuelve aún el problema del nombre del movimiento, pero nos da algunas luces para comprender el propósito de quienes le integraron.

Al menos 70 años antes del surgimiento del Expresionismo, Eugene Delacroix había expresado que "la pintura es un puente lanzado entre las almas". ${ }^{4}$ Con ello debemos inferir que la pintura habla y replica al alma del espectador desde el alma del artista. Sin duda se trata de una conexión especial, pero Delacroix no va a agotarla completamente, ni siquiera llegará a desarrollarla al máximo. Esta tarea quedará para el siglo $\mathrm{XX}$.

La conciencia de sí mismo que el individuo impulsa desde el Renacimiento verá sus mejores frutos en el siglo XIX. Tal vez ninguna época anterior haya provisto al ser humano de una mayor conciencia de su maravillosa capacidad y de su abismal limitación, en los campos más diversos. Juega el hombre decimonónico al héroe, pero también al ser ávido de redención. El siglo XX le propinará la bofetada de la decepción al gritarle en la cara que no es un titán, pero tampoco es una víctima inocente.

Es justamente es ese instante cuando la fosa insondable de su interioridad hará erupción, no sin el dolor que produce arrancarse un trozo de sí mismo. Hermann Bahr (1863-1934), escritor y dramaturgo austriaco, en un ensayo publicado en 1916 expresa:

\footnotetext{
${ }^{2}$ Nobert Lynton en Stangos, 1989, p. 31.

${ }^{3}$ Los humanistas italianos del siglo XV ya hablaban de las incuestionables posibilidades del ser humano para desarrollarse en este mundo y alcanzar la gloria terrenal a través de sus logros y hazañas. Basta sólo leer las obras de Gianozzo Manetti (De dignitate et excellentia hominis, 1451) o Giovanni Pico Della Mirandola (Oratio de hominis dignitate, 1486). De modo pues que esta idea ganó en madurez en los siglos subsiguientes y durante el siglo XIX, de una u otra manera, podemos ya afirmar que el hombre busca trascender a través de dos vías: la razón y la pasión o el espíritu.

${ }^{4}$ Eugene Delacroix citado por Huyghe, 1968, p. 90.
} 
El hombre ha sido privado del alma; la naturaleza ha sido privada del hombre... nunca tan sepulcral silencio ha reinado en el mundo. Nunca el hombre fue tan pequeño. Nunca estuvo más inquieto... El hombre pide gritando su alma... También el arte grita en las tinieblas, pide socorro e invoca al espíritu: es el expresionismo. ${ }^{5}$

Tal vez con esto ya estemos entrando en terrenos más coherentes que nos hagan aceptar el nombre del movimiento del que hablamos aquí. No obstante, resta aún un detalle que el pensamiento de Henri Bergson (1859-1941) puede explicarnos mejor. Mientras el siglo XIX se debatía entre las magníficas propiedades de la capacidad racional del hombre y de la amplia dimensión espiritual del mismo, este filósofo francés añade un tercer elemento, una especie de tercera vía en la manera de relacionarnos con el mundo. Bergson nos habla de la intuición como el único medio que nos puede brindar un conocimiento real de las cosas, sin intervenciones racionales ni alteraciones emocionales derivadas de las sensaciones.

La intuición de la que habla Bergson, implica procesos instantáneos, inmediatos, de análisis y síntesis, imposible de ser separados y permeados por elementos emocionales. La fusión entre el sujeto y el objeto en una sola realidad a partir de la intuición, es para este filósofo la única manera de conocer lo real.

En este sentido, para el movimiento que estudiamos, expresión no es lo mismo que decir representación de un sentimiento a modo de exteriorización. Los expresionistas buscan totalizar la vida en la aprehensión de un instante del ser, en su más compleja y profunda interioridad. "No se trata de expresar algo ajeno sino esa profundidad del ser que no admite predicados de observación ni de intelección, ni siquiera de sentimiento porque implican siempre una voluntad de comunión extrapersonal". 6

A estas alturas, si afirmamos que el Expresionismo no es más que un símbolo de la expresión misma del hombre, seguramente no estaremos tan lejos de la realidad. Los expresionistas trabajan alrededor de la idea absoluta de la existencia, con todos sus defectos, su dolor, su soledad, su patetismo, su arrebato y su vehemencia. Si los cubistas buscan la esencia del objeto, lo que hay de absoluto en él, los expresionistas se decantan por la propia existencia. Pero así como los cubistas no buscan la esencia de una guitarra específica, sino de la guitarra en el absoluto, los expresionistas no exacerban su individualismo de artistas trabajando sobre su esencia personal, sino que persiguen el lenguaje de la humanidad entera (universal).

Es por ello que los expresionistas, contrario a lo que normalmente se piensa, no se mueven en un mundo individualizado, representando realidades personales, sino que su labor debe llevarse a cabo en medio de lo que a todos les es dado conocer. Esto explica por qué, al repasar el legado del Expresionismo, nos hallamos con un tronco común que divaga entre lo primitivo, lo fantástico, lo religioso, lo erótico, etc. Sin embargo, y paradójicamente, el Expresionismo es, quizás, la corriente de principios del siglo XX que más reafirma la individualidad del artista, pues aunque se

\footnotetext{
${ }^{5}$ Hermann Bahr citado por De Micheli, 1979, pp.73-74.

${ }^{6}$ Romero Brest, 1952, p. 51.
} 
busca lo absoluto en la visión de la realidad, nunca esta visión es absoluta, sino personal. $^{7}$

Todo lo anterior, sin embargo, podría desintegrarse si admitimos que a quienes denominamos hoy expresionistas, poco les agradaba ser calificados de tal modo. ${ }^{8}$ No es extraño que se manifestaran abiertamente molestos ante el uso de este calificativo, pues para ellos jamás fue un objetivo la representación de la pura expresión. Esto sólo corresponderá, al menos en intención, a otros que derivan a las formas abstractas en la pintura. ${ }^{9}$ Incluso, la ya legendaria afirmación de Oscar Wilde (1854-1900), el arte no expresa nada salvo a sí mismo, no va a hallar aún el momento de su materialización y el Expresionismo no será, en modo alguno, su primera víctima.

En el marco de esta compleja, pero no menos interesante situación, no es descabellado afirmar que el Expresionismo se parece más a una bruma espesa y difusa que se cierne sobre Europa central y embarga a un grupo de individuos en extremo sensibles en una aventura exploratoria, igualada sólo, tal vez, por la de aquellos precursores e impulsores del goticismo romántico de finales del siglo XVIII. La de los expresionistas es una exploración de características casi místicas, como hemos podido inferir, pero también es una exploración plástica y esto no podemos negarlo.

Antes, durante y después de la Primera Guerra Mundial (1914-1918) el Expresionismo desborda sus más caros objetivos, así como los de las demás vanguardias que habían surgido en latitudes vecinas. El Futurismo, el Fauvismo, el Cubismo no hallaron suelo fértil en la zona germánica más que para fundirse entre ellos en una especie de movimiento moderno que penetró la búsqueda expresiva de los artistas allí radicados. Este es el origen de la plástica expresionista. Una plástica que absorbe y transmuta los elementos característicos de otras. Tal vez por ello sea tan difícil precisarla y describirla sin contradecirnos, sin tropezarnos con obvias paradojas.

Pero sería injusto reducir la plástica y el concepto estético de los expresionistas a una mezcla aleatoria de elementos del Fauvismo, el Cubismo y el Futurismo. Si ha resultado lioso dar con el porqué del calificativo al tipo de manifestación artística a la que nos hemos referido aquí, mucho más complicado resulta dar una relación, más o menos coherente, de influjos en torno a aquello que los expresionistas concretan en su plástica. No obstante, es una labor ineludible.

\footnotetext{
${ }^{7}$ El grupo de Munich, Der Blaue Reiter, guiado por Vassily Kandinsky y Franz Marc, fue el que mayor preocupación mostró por la necesidad de un lenguaje universal en el arte. Este tema, interesante por demás, escapa de los objetivos de una aproximación histórica al Expresionismo, sin restarle en lo más mínimo la capital importancia que merece.

${ }^{8}$ Ernst Ludwing Kirchner (1880-1938), hoy uno de los más reconocidos expresionistas, declaró en 1924 que "encontraba más humillante que nunca... ser identificado con Munich y el expresionismo" [Ernst L. Kirchner citado por Willet, 1970, p. 6]. Es probable, no obstante, que Kirchner se refiriera con el término expresionismo al grupo Der Blaue Reiter, conformado en la ciudad de Munich en 1911 y al que consideró de disímiles objetivos a los de Die Brücke, grupo al cual él pertenecía desde 1905.

${ }^{9}$ Ver Romero Brest, 1979, p. 53 y ss.
} 
Pensemos un momento en los cambios sustanciales acaecidos en la vida cotidiana de las personas con el ingreso en ella del automóvil, el teléfono, el gramófono, el avión, el cinematógrafo e incontables e ingeniosos inventos tecnológicos. La transmutación en el modo de vida era más que radical, sobre todo en las grandes ciudades europeas. Lo que era denominado modernidad parecía haber caído como una gran nevada durante la noche y no había dado oportunidad alguna para que la costumbre a las cosas nuevas terminara por asentarse.

El cambio trajo consigo no sólo el asombro ante la novedad y el placer de ver solventados ciertos inconvenientes (como la comunicación y el traslado), sino también un sentimiento de agobio y deseo de evasión hacia lo primitivo, que se hace patente en el gusto e interés por los estudios antropológicos de culturas disímiles a la occidental europea. ${ }^{10}$ Era común entonces que los artistas miraran en lo primitivo la oportunidad de redención, la ausencia de toda corrupción. ${ }^{11}$ El novelista francés Charles-Louis Philippe (1874-1909) escribía en 1894: "Ahora necesitamos algunos bárbaros... La era de las pasiones empieza hoy". ${ }^{12}$

Pero la Historia del Arte como disciplina también contribuyó con la configuración de la plástica expresionista. Sin proponérselo, se rescataba y resaltaba, como novedad, la obra de algunos artistas y estilos degradados a los oscuros sótanos del olvido. El historiador alemán del arte, Max J. Friedländer (1867-1958) elabora un monumental estudio sobre el pintor germano Mathias Grünewald (h. 1470-1528), el cual es publicado en varios volúmenes entre 1907 y 1911. El impacto en los jóvenes artistas fue inmediato y el asombro ante lo que constituía una expresión "característicamente teutónica" llenó de comentarios los cafés de ciudades como Dresde y Munich. Tanto es así que el interés por Grünewald prácticamente aparece en la escena germana después de publicados los estudios de Friedländer, pues anteriormente las obras de este pintor del siglo XVI era casi una molestia para los propios museos. ${ }^{13}$

Pero lo mejor estaba por salir a la luz. El también historiador del arte Julius MeierGraefe (1867-1935), luego de realizar un periplo por España, publica en 1910 su obra Viaje español (Spanische Reise). En ella destaca la figura de El Greco (15411614), a quien describió como un artista expresionista. Dos años antes, en 1908, el reputado historiador Wilhem Vöge (1868-1952) había inaugurado su seminario de historia del arte en el Instituto de Arte de Freiburg con un análisis re-evaluativo del Manierismo en la pintura italiana del siglo XVI, calificándole de estilo anti-clásico. Walter Friedländer (1873-1966), colega de Vöge, se sintió estimulado por las

\footnotetext{
10 Puede verse al respecto el trabajo de Juan José Sebreli, El asedio a la Modernidad, Editorial Sudamericana, Buenos Aires, 1995.

${ }^{11}$ Vale acotar que el imperialismo europeo de las últimas décadas del siglo XIX había conquistado importantes regiones en África y en la Micronesia (Océano Pacífico). Esto permitió el conocimiento de algunas culturas que, hasta entonces, vivían sin haber tenido contacto alguno con Occidente, por lo tanto consideraras "puras" o "primitivas". Sus expresiones artísticas llegan a Europa como muestras exóticas, pero pronto pasan a ser el centro de interés de los artistas que buscaban nuevas formas de expresión plástica.

${ }_{12}$ Charles-Louis Philippe citado por Willet 1970, p. 20 [Las novelas de Philipe se distinguieron por su marcada piedad por los desposeídos de la sociedad y por su particular habilidad para describir con crudeza la miseria de los más pobres.]

${ }_{13}$ Puede verse al respecto el libro de Shearer West, The visual arts in Germany (1890-1937): utopia and dispair, Rutgers University Press, New Jersey, 2001.
} 
opiniones de su compañero sobre una pintura obviada descaradamente por los historiadores y se dedicó a su estudio y reivindicación, publicando dos grandes investigaciones sobre la pintura manierista en la década de $1920 .^{14}$

Bajo el ala de Wilhem Vöge y Walter Friedlander se educaba el joven Erwin Panofsky (1892-1968), quien realiza su disertación de grado en 1914 sobre las teorías artísticas del eximio pintor alemán y contemporáneo de Grünewald, Albrecht Dürer (1471-1528) y publica luego, en 1924 su obra Idea, en la cual analiza el trasfondo filosófico del Manierismo. Otras contribuciones dignas de mención son los estudios realizados por los también alemanes Werner Weisbach (1873-1953) y August Liebmann Mayer (1885-1944) sobre la pintura de El Greco y Francisco de Goya (1746-1828), respectivamente, luego de la primera década del siglo XX.

No cabe duda que los historiadores del arte, enfocándose en las manifestaciones de otros tiempos, estaban leyendo a su propia época. Al menos así puede inferirse del análisis que Max Dvořák (1874-1921) realizará sobre el arte del siglo XVI en su artículo El Greco y el Manierismo, publicado en 1920:

No hacen falta muchas palabras para explicar por qué estaba condenado El Greco a ir siendo paulatinamente olvidado en los siglos siguientes, siglos dominados por las ciencias naturales, el pensamiento materialista, la fe en la causalidad y el progreso técnico, en que la civilización era mecanización, de ojos y de cerebro, pero no de corazón... [En esta última generación] la literatura y las artes se han orientado hacia los absolutos espirituales, como en la Edad Media y en la época del Manierismo, y han vuelto la espalda a la fidelidad y a la naturaleza sensible... La misteriosa ley del destino parece guiarnos hacia una nueva época espiritual y anti-materialista... ${ }^{15}$

La alusión a lo que mencionábamos párrafos atrás, en relación a la manera en que el Expresionismo establece una relación entre absolutos espirituales con la realidad y su esencia anti-materialista, quedan claramente planteadas por este historiador checo. Los rasgos que no pocos historiadores habían identificado para calificar como estilo degenerado al arte del siglo $\mathrm{XVI}^{16}$ se perfilaban ahora como motivos subjetivos y expresivos de un estilo que hablaba de una profunda crisis espiritual. Esto, por si fuera poco, fue potenciado por Wilhelm Worringer (1881-1865) en 1908 cuando publica su breve disertación doctoral Abstracción y empatía (Abstraktion und Einfühlung), en la cual expone con claridad las posibilidades e inclinaciones espirituales del arte en torno a la naturaleza y la abstracción.

Como podrá observarse la contribución de la historiografía del arte a la búsqueda de los jóvenes artistas alemanes que se unirán en dos significativos grupos, Die Brücke y Der Blaue Reiter, no fue pequeña ni desdeñable. Desechemos entonces el común error de considerar al Expresionismo como un movimiento sin deudas y/o puramente autónomo, cuando su cualidad de movimiento moderno reside en lo profundo que sus raíces están hundidas en su propio tiempo y en el pasado que le impulsa.

\footnotetext{
${ }^{14}$ El primero de estos estudios versó sobre lo que él llamó la pintura manierista temprana, publicado en 1925 y, el segundo, se concentró en la pintura manierista tardía, aparecido en 1929.

${ }_{15}$ Max Dvořák citado por Gombrich 1984, p. 225-226.

${ }^{16}$ Heinrich Wöfflin es tal vez el historiador más tajante en referencia al rechazo del arte manierista.
} 
En 1905, cuatro jóvenes estudiantes de arquitectura en Dresde, conforman la asociación artística de nombre Die Brücke (El Puente). Ellos eran: Erich Heckel, Karl Schimdt-Rottluff, Fritz Bleyl y Ernst L. Kirchner. Para entonces estaban impresionados por lo que habían visto en el Museo de Etnografía de esta ciudad alemana: el arte primitivo les había revelado la posibilidad de un nuevo lenguaje de expresión artística y estaba deseosos por experimentar con él. Sentían que estaban ante la posibilidad cierta de desembarazarse de la tradición plástica que impedía la floración de lo ingénito en la relación entre el hombre y la realidad. Lo primitivo lucía como aquello que no había sido corrompido por la sociedad materialista en la cual vivían y a la cual deseaban cambiar para mejor.

Schmidt-Rottluff propuso el nombre para el grupo a partir de un pasaje de la obra Así habla Zaratustra (Also sprach Zarathustra, 1883-1891) de Friederich Nietzche (18441900) que reza así: "La grandeza del hombre está en ser un puente y no una meta: lo que en el hombre se puede amar es un tránsito y un ocaso".

El nombre escogido no es casual ni caprichoso. Todos eran muy conscientes del tiempo que vivían y su búsqueda no era nueva a pesar de su juventud. Su intención era convertirse literalmente en un puente que vinculara el arte que crearían, que nacería de sus experimentos, con la sociedad. $Y$ aunque cabría esperar una participación activa de estos entusiastas muchachos en asuntos más allá del plano artístico (actividades sociales o políticas), lo cierto es que nunca actuaron un centímetro más lejos de sus papeles y lienzos. La construcción de su puente requería un trabajo interior demasiado grande como para hacer proselitismos de calle.

Pero Die Brücke tampoco fue una simple alianza de unos jóvenes ávidos de propiciar e impulsar cambios a nivel artístico. Era más bien una comunidad al mejor estilo de sus antepasados los Nazarenos, ${ }^{17}$ que pretendía establecer un nuevo modo de considerar el arte y la vida. Su pintura no era simple cuestión de formas nuevas, era asunto de nuevas relaciones con el mundo.

Kirchner, el miembro más destacado de Die Brücke, reflexionará sobre la pintura y su relación con la realidad, que es donde radica la complejidad del Expresionismo en general. Sin perder de vista lo que hablábamos de Bergson algunos párrafos atrás, traemos a colación lo que este pintor pensaba sobre la estética de su pintura. Para él, la superficie pintada es una especie de "jeroglífico" que condensa la forma, el sentimiento y la agitación de un instante. ${ }^{18}$ De aquí a la pura abstracción expresiva hay sólo un paso.

Los miembros de Die Brücke deseaban por encima de todo preservar la frescura y la inocencia en las sensaciones, la fuerza y la honestidad en su visión de la realidad. Por esta razón desdeñaron el análisis de lo que se ve, así como su interpretación emocional. La esencia de su anhelo radicaba es su principal objetivo: captar eso que creían que no podía ser enseñado. ${ }^{19}$

\footnotetext{
17 Los Nazarenos constituyen un grupo artístico alemán, creado alrededor de la Academia de San Lucas y que propiciaba, a inicios del siglo XIX, un rescate de la esencia del arte religioso cristiano según sus más puros basamentos estilísticos anclados en el Renacimiento clásico italiano.

${ }_{18}$ Romero Brest 1979.

${ }^{19}$ Dube 1972.
} 
Algunos años después de la conformación del grupo de Dresde, en 1911, se configura en Münich un segundo grupo de artistas de características similares a Die Brücke. Se trata de Der Blaue Reiter, fundado por Wassily Kandinsky (1866-144) y Franz Marc (1880-1916). El nombre del grupo se lo deben a un trivial acuerdo: a Marc le gustaban los caballos, a Kandinsky le gustaban los jinetes y a ambos el color azul. Su primera actividad fue organizar una exposición, la cual se llevó a cabo en la Galería Thannhauser de Munich y reunió a artistas tan disímiles como Auguste Macke, Gabriele Münter, Robert Delaunay, Heinrich Campendonk, Henri Rousseau y los propios Kandinsky y Marc.

Era obvio que Der Blaue Reiter sería todo menos un grupo homogéneo. De nuevo, así como en el Expresionismo nunca existió una unidad de estilo, en el grupo de Münich tampoco la hubo. No obstante, este grupo no sólo se propuso reunir a artistas con objetivos afines, sino también realizar algunas actividades complementarias que impulsaran estos objetivos. Es así como nace la idea, de la mano de Kandinsky, el más experimentado del grupo, de publicar, según sus propias palabras, "una especie de almanaque con reproducciones y artículos... En el libro debe reflejarse todo el año, y una cadena hacia el pasado y un rayo de luz hacia el futuro deberían proporcionar a este espejo plena vida..."20

Justamente es en los escritos aparecidos en la única publicación del Almanaque de Der Blaue Reiter, en 1912, donde podemos hallar la más clara expresión de lo que estos artistas se planteaban como objetivos, uniéndose así, muy a pesar del parecer de los miembros de Die Brücke, a lo que estos buscaban. Como el grupo de Dresde, los jinetes buscaban la renovación de la pintura, pero no desde el mero espacio plástico sino incluso y sobre todo desde su esencia.

Así, el arte es para ellos un vínculo necesario entre el hombre y la verdad de las cosas. Un puente, como ya habían expresado los miembros de Die Brücke, pero aún más porque para Der Blaue Reiter el arte era una puerta de acceso a un nuevo universo. Según expresó Kandinsky el objetivo del arte es ahora "volver por otro camino a las imágenes abstractas y misteriosas de la vida interior, que está regida por leyes distintas de las que la ciencia descubre en la naturaleza". ${ }^{21}$

En parte, ese nuevo acceso a la interioridad humana la realiza el grupo de Munich a través de su admiración por los maestros del pasado que la historia del arte se empeñaba en devolver a la luz pública. Paradigmática es la admiración que sienten por Grünewald y Dürer, sobre todo por este último, quien les brinda estupendas lecciones en sus actividades gráficas (grabados y la propia actividad básica de dibujar). Antológica es también la admiración profesada por la obra de El Greco, sobre quien Marc llegaría a decir en un artículo para el citado almanaque que "la glorificación de este gran maestro está íntimamente ligada al florecimiento de nuestras nuevas ideas artísticas". ${ }^{22}$ Le llega incluso a llamar "el viejo místico" e identifica la concepción que el pintor greco-español poseyera del mundo como "la mística construcción interior, que es el problema de la generación actual". ${ }^{23}$

\footnotetext{
${ }^{20}$ Vassily Kandinsky citado por Josep Casals en Kandinsky y Marc 198, p. 10.

21 Ibidem, pág. 12.

${ }_{22}^{2}$ Franz Marc en “Bienes espirituales”, en Kandinsky y Marc 1984, p. 34.

${ }^{23}$ Idem.
} 
No es difícil observar que, así como ya lo había propuesto Die Brücke, Der Blaue Reiter tenía muy claro el terreno en cual habría de desenvolverse el arte de ahora en adelante. "Todos ellos estaban convencidos de que la función de la obra de arte sólo consistía en la expresión de un sentimiento vital intenso..."24

Pero el Expresionismo no se reduce a estos dos grupos. Hubo más, mucho más de lo que podríamos exponer en este ensayo. Fuera de Alemania, en Austria no podemos dejar de destacar la extraordinaria labor de Egon Schiele (1890-1918), quien en una corta de carrera de 10 años dejó en Viena una de las más intensas muestras de la esencia expresionista. Agregaremos que algunos de los fundadores de los grupos mencionados murieron en combate en la Primera Guerra Mundial, como es el caso de Franz Marc. Otros sobrevivieron a la incursión bélica y otros siguieron trabajando durante la guerra. ${ }^{25}$ Aunque ni Die Brücke ni Der Blaue Reiter perduraron después del conflicto bélico, ${ }^{26}$ la estela del Expresionismo aún tenía mucho que dar. En la década de 1920 se desarrolló la segunda generación de expresionistas, a veces calificados como post-expresionistas. Sea cual fuere el término correcto para llamarles, lo cierto es que artistas como Max Beckmann (18841950), George Grosz (1893-1959) y Otto Dix (1891-1969) Ilevaron la antorcha de la angustiosa búsqueda de sus predecesores a límites insospechados.

La diferencia entre esta segunda oleada de expresionistas alemanes en relación a la primera, radica en el apego que mantuvieron siempre a la figuración, descartando cualquier posibilidad de abstracción en sus obras. Para ellos la abstracción no era, como sí lo fue para no pocos de los primeros expresionistas, un camino válido. Estos relevos veían como un deber ineludible la crítica social, el plasmar en sus obras el desastre que era la sociedad en la cual vivían y, en este sentido, eran algo menos utópicos que los primeros. No obstante, aun esperaban generar con su arte algún cambio, lo cual terminó siendo una actitud puramente romántica.

Del Expresionismo alemán podemos resaltar aún su influencia en los primeros años de la celebérrima Bauhaus, escuela de arte y diseño creada en 1919 en la ciudad alemana de Weimar, sede del nuevo gobierno de post-guerra. Walter Gropius (18831969) fue su primer director y había participado de no pocas actividades junto a los expresionistas. Su primera plantilla de docentes incluyó a nombres clave del Expresionismo como Wassily Kandinsky, Paul Klee (1879-1940) y Johannes Itten (188-1967). Sin embargo, para 1922 Gropius tuvo problemas con estos profesores quienes se opusieron rotundamente a realizar cambios en sus métodos que "resaltaban la expresión artística del individuo por una participación objetiva en el campo del diseño socialmente útil". ${ }^{27}$ Itten abandonó la Bauhaus en 1923, aunque Kandinsky y Klee permanecieron algunos años más.

Para 1933, Ludwing Mies van der Rohe (1886-1969) dirigía la Bauhaus cuando ésta fue clausurada por el régimen Nazi. Desde los años 20 el partido Nacional Socialista Alemán se había opuesto a esta escuela por considerarla un peligro social y un nido

\footnotetext{
${ }^{24}$ Vogt 1980, p.12.

${ }^{25}$ Kart Schimdt-Rottluff sirvió en el ejército alemán y sobrevivió a la guerra.

${ }^{26}$ Der Blaue Reiter se disuelve en 1914, mientras Die Brücke ya se había disuelto antes de mediados de 1913.

${ }^{27}$ Norbert Lyndon en Stangos 1989, p. 44.
} 
de comunistas, debido a la presencia de profesores rusos en ella. Pero la Bauhaus no fue la única víctima de los nazis en el ámbito artístico. En los años treinta, el gobierno nazi clausuraría museos y galerías de arte moderno a lo largo y ancho del país.

Adolf Hitler (1889-1945) diría en un mitin de celebración de un aniversario más del Partido celebrado en Nuremberg en 1935: "El papel del arte no es revolcarse con fruición en la inmundicia, su misión nunca será reproducir la descomposición, dibujar cretinos para simbolizar la maternidad, pintar jorobados subnormales para representar la fuerza viril". 28

Es obvio que al führer no le gustaba un arte que hiciera las veces de espejo de la realidad, sino un arte que proporcionara modelos ejemplares y visiones idílicas del imperio alemán que habría de durar mil años. ${ }^{29}$

El 19 de julio de 1937, el mismo Hitler inauguró en Munich una exposición denominada Arte Degenerado (Entartete Kunst), tan sólo un día después de la Gran Exposición de Arte Alemán que sería su complemento. En la primera se exhibían las obras de los "ismos" de los primeros años del siglo XX: Cubismo, Futurismo, Dadaísmo, Expresionismo, todos habían sido metidos en un mismo saco y debían quedar a partir de entonces sencillamente excluidos de la Historia del Arte. La exposición reunía más de 600 obras (esculturas y pinturas), realizadas por más de 100 artistas. $^{30}$

La vieja Galería Hofgarten, donde tuvo lugar la exposición de Arte Degenerado, albergó obras de Kirchner, Kandisnky, Beckmann, Heckel, Kokoschka, Klee, Marc y Nolde, por mencionar sólo algunos de los pintores expresionistas incluidos. Las obras se colgaron amontonadas, muchas sin marco y "con etiquetas tan ofensivas que algunas le parecieron demasiado fuertes al propio Hitler." ${ }^{31}$ La prensa se hizo eco del ataque gubernamental a las artes y proclamaba abiertamente que "el templo del arte alemán ha quedado definitivamente limpio". ${ }^{32}$ Más de dos millones de personas visitaron la exposición y, aunque puede no resultar un consuelo pensar

\footnotetext{
${ }^{28}$ Adolf Hiltler citado por Adam 1992, p. 121.

${ }^{29}$ Es conveniente destacar que ya en 1892, el periodista y crítico de arte alemán Max Nordau (18491923) escribió el tratado Entartung (Degeneración), en el que degradaba al movimiento prerrafaelista inglés y a los simbolistas franceses, tachándolos de perturbados mentales -de nuevo, degenerados-, y proclamaba la superioridad de la cultura alemana. Algunos años antes, en 1883, Nordau había publicado su obra más conocida Mentiras convencionales de nuestra civilización, en la cual arremetía contra la irracionalidad y el nihilismo. Lo curioso del asunto es que Nordau era judío, aunque no practicante, y sólo en 1895 vuelve con entusiasmo a las prácticas del Judaísmo cuando conoce la idea de un Estado Judío expuesta por Theodor Herzl. Empero, el tratado de Nordau antes citado, junto con otros relativos al racismo y a la superioridad de la cultura alemana, fueron cruciales en la configuración de la ideología del Nacionalsocialismo. Por otro lado, no debemos olvidar tampoco que el propio Hitler era un pintor frustrado, detalle éste que no debe pasarse por alto tan fácilmente.

${ }^{30}$ Luego de clausurada la exposición, las obras fueron vendidas a marchantes de arte, la mayoría de ellos extranjeros. Sin embargo, en 1939, a raíz de una nueva ola de confiscaciones de obras de arte degenerado, fueron quemadas en Berlín más de 1000 óleos y casi 4000 acuarelas y dibujos.

Sobre este tema puede verse el detallado y completo trabajo de Lynn $\mathrm{H}$. Nicholas, The rape of Europe, Ramdom House, N.Y., 1995.

${ }^{31}$ Adam 1992, p. 123.

${ }^{32}$ Adam 1992, p. 125.
} 
que la mayor parte de los asistentes acudieran a ella a rendir un último homenaje a las expresiones artísticas que sentían más cercanas, nosotros preferimos pensar así.

Los artistas alemanes de la vanguardia, la mayoría de ellos expresionistas, se convirtieron entonces en enemigos del estado y amenazas para la nación alemana. Kirchner se suicidó en 1938 durante su exilio en Suiza; Paul Klee se exilió también en Suiza pero en virtud de su calidad de artista degenerado no pudo obtener la ciudadanía de ese país; Beckmann voló a Ámsterdam el mismo día de la inauguración de la exposición en Munich; Kandinsky ya había dejado Alemania en 1933 cuando fue clausurada la Bauhaus y se hace ciudadano francés en 1939; Nolde y Schmidt-Rottluff permanecieron en Alemania, pero les fue terminantemente prohibido pintar.

Pareciera que allí muere el Expresionismo. Sin embargo, estamos muy lejos de la verdad. Si alguna de las vanguardias de comienzos del siglo XX tiene alguna pervivencia consistente, es el Expresionismo. Otras latitudes le reciben y acogen con los brazos abiertos. En el México revolucionario, José Clemente Orozco (1883-1949) es quien mejor atrapa el objetivo expresionista como lo expusieron los miembros de Die Brücke. El artista estadounidense de origen holandés Willem de Kooning (19041997) asume el Expresionismo como una vía expedita a la pura expresión individual en el campo de la abstracción gestual. Junto a él podemos situar a Jackson Pollock (1912-1956) y a Arshile Gorky (1904-1948).

De modo pues que el camino de este singular movimiento artístico que en un momento comparábamos con una bruma espesa y difusa, terminó convirtiéndose en el hálito de vida surgido de las entrañas mismas del desasosiego humano que no concluye con él, ni agota sus posibilidades en sí mismo. Si los asuntos del espíritu hallan abrigo en el mundo medieval y posteriormente explotan de nuevo en la crisis manierista; si el Barroco asumió lo espiritual como razón indispensable para luego heredarlo al Romanticismo y su vorágine pasional, entonces el Expresionismo alemán hizo del espíritu humano un destructor de castillos, como bien expresó Franz Marc en 1912, dos años antes de que la guerra que acabaría con todas las guerras impulsara el grito de horror por toda Europa.

\section{BIBLIOGRAFÍA}

A.A.V.V. (2000). Descubrir las vanguardias. Madrid: Arlanza Ediciones.

Adam, P. (1992). El arte del Tercer Reich. Barcelona: Editorial Tusquet.

Chacón Fuertes, P. (1988). Bergson. Madrid: Editorial Cincel.

Combalia, V. et al. (1980). El descrédito de las vanguardias artísticas. Barcelona: Editorial Blume.

De Micheli, M. (1979). Las vanguardias artísticas del siglo XX. Madrid: Alianza Editorial. 
Dube, Wolf-Dieter (1972). The Expressionists. Londres: Thames \& Hudson.

Durant, Will (1963). The story of philosophy, Washington Square Press Books, N.Y.

Elger, D. (1990). Expresionismo. Una revolución artística alemana. Colonia: Tashen.

Gombrich, E. (1984). Norma y Forma. Madrid: Alianza Editorial.

Huyghe, R. (1968). Los Poderes de la Imagen. Barcelona: Editorial Labor.

Kandinsky, V. y Franz M. (1984). El Jinete Azul. Barcelona: Ediciones Paidós.

Nicholas, Lynn H. (1995). The rape of Europe. New York: Random House.

Romero Brest, J. (1979). La pintura del siglo XX. México: F.C.E.

Sebreli, J. J. (1995). El asedio a la Modernidad. Buenos Aires: Editorial Sudamericana.

Stangos, N. (Coord.) (1989). Conceptos del arte moderno. Madrid: Alianza Editorial.

Vogt, P. (1980). Der Blaue Reiter. Barcelona: Editorial Blume.

West, S. (2001). The visual arts in Germany (1890-1937): utopia and despair. New Jersey: Rutgers University Press.

Willet, J. (1970). El rompecabezas expresionista. Madrid: Ediciones Guadarrama.

The Dictionary of art historians. Recuperado de http://www.lib.duke.edu/lilly/artlibry/dah/ 